\section{GYNAECOLOGICAL PSYCHIATRY}

\section{A PRELIMINARY REPORT ON AN EXPERIMENTAL CLINIC}

BI

\section{LINTON SNAITH, M.D., M.S., F.R.C.S., M.R.C.O.G. \\ AND}

BRENDA RIDLEY, B.A., M.B., Ch.B.

From the Department of Obstetrics and Gynaecology, Newcastle-upon-Tyne General Hospital

The value of the ad hoc psychiatric clinic in the treatment of gynaecological disorder is being slowly accepted even by the most conservative of practitioners, but such clinics have the disadvantage that they tend to take the patient out of the environment to which she has turned for advice and to treat her purely on psychological lines. In order to avoid this segregation it was decided to establish, on an experimental basis, sessions for the psychiatric investigation and treatment of cases referred with gynaecological symptoms. Some of these patients were plainly victims of an anxiety state, with no evident physical cause for their symptoms, but there were others with definite pelvic lesions needing gynaecological investigation and treatment whose symptoms were not entirely compatible with the physical findings.

In the following description of the work of this "clinic within a clinic" we have attempted to summarize the impressions formed during two years' work and to show that there is room for such a clinic within a gynaecological department. We have made no attempt to put forward any original views on the aetiology or treatment of gynaecological ailments, and the opinions expressed under various headings are not intended to have the weight of vast experience or to imply that our beliefs are already fixed concerning these matters. It is hoped that the results of this experiment will stimulate others to offer their experiences for discussion.

The clinic was established to serve a double purpose: (a) to assess the degree to which somatic symptoms in particular cases were influenced by psychological factors, and (b) to give such short-term psychotherapy as was practicable. Cases referred by the gynaecologist comprised those in which psychoneuroses were obvious and those in which the physical findings were insufficient to account for the patients' symptoms. Personality, heredity, constitution, and life history were studied in each patient and an attempt was made to assess the incidence and relative potency of aetiological factors leading to the development of psychoneurotic disturbances (Table 1), and correlate such factors with the somatic symptoms presented (Table II).

TABLE I.-Incidence of Aetiological Factors in Neurosis of 165 Patients

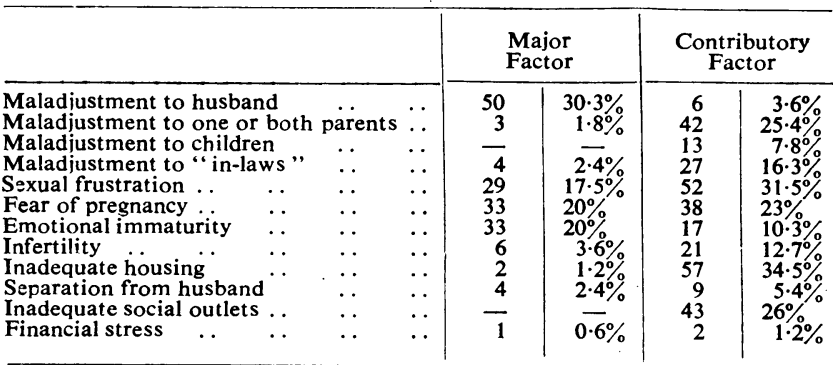

Of 165 patients with psychoneuroses of varying degrees of severity, $77(46 \%)$ were considered to possess psychologically unstable constitutions. The majority of these gave
Table II.-Relation of Symptoms to Psychological Stress Factor

\begin{tabular}{|c|c|c|c|c|c|c|c|c|c|c|c|c|}
\hline & 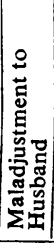 & 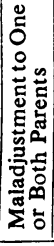 & 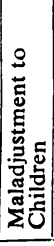 & 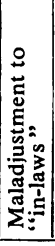 & 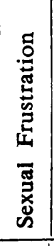 & 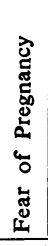 & 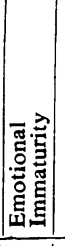 & 苞 & 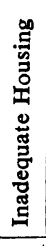 & 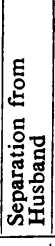 & 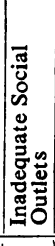 & 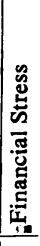 \\
\hline $\begin{array}{l}\text { Total incidence of } \\
\text { each stress factor } \\
\text { (see Table I) }\end{array}$ & 56 & 45 & 13 & 31 & 81 & 71 & 50 & 27 & 59 & 13 & 43 & 3 \\
\hline Dyspareunia & 15 & 12 & 0 & 7 & 29 & 18 & 19 & 10 & 21 & 5 & 6 & 0 \\
\hline $\begin{array}{c}\text { (no orgasm) } \\
+ \\
+\end{array}$ & 18 & 9 & 5 & 5 & 30 & 12 & 7 & & 12 & 3 & 3 & \\
\hline $\begin{array}{ll}\text { Libido }+ & . .\end{array}$ & 12 & 12 & 0 & 2 & 12 & 10 & 13 & 5 & 6 & 1 & 3 & 0 \\
\hline Non-consummation & 2 & 1 & $\begin{array}{l}0 \\
0\end{array}$ & $\begin{array}{l}2 \\
4\end{array}$ & $\begin{array}{r}7 \\
20\end{array}$ & $\begin{array}{l}5 \\
0\end{array}$ & $\begin{array}{l}9 \\
9\end{array}$ & $\begin{array}{r}2 \\
27\end{array}$ & $\begin{array}{l}4 \\
7\end{array}$ & $\begin{array}{l}0 \\
1\end{array}$ & $\begin{array}{l}2 \\
2\end{array}$ & $\begin{array}{l}\mathbf{0} \\
\mathbf{0}\end{array}$ \\
\hline norrhoea $\quad .$. & 9 & 9 & 2 & 5 & 21 & 13 & 11 & 4 & 12 & 1 & 4 & 1 \\
\hline $\begin{array}{l}\text { Menorrhagia } \\
\text { Irregular haemor- }\end{array}$ & $\begin{array}{l}4 \\
7\end{array}$ & $\begin{array}{l}2 \\
5\end{array}$ & $\begin{array}{l}2 \\
0\end{array}$ & $\begin{array}{l}3 \\
8\end{array}$ & $\begin{array}{l}13 \\
13\end{array}$ & $\begin{array}{r}8 \\
10\end{array}$ & $\begin{array}{l}4 \\
3\end{array}$ & $\begin{array}{l}2 \\
2\end{array}$ & $\begin{array}{l}5 \\
7\end{array}$ & $\begin{array}{l}2 \\
0\end{array}$ & $\begin{array}{l}2 \\
5\end{array}$ & 1 \\
\hline $\begin{array}{l}\text { rhage } \\
\text { Amenorrhoea and }\end{array}$ & 3 & 2 & 0 & $2^{\circ}$ & 6 & 1 & 2 & 3 & 2 & 0 & 1 & 0 \\
\hline oains $\quad \ldots$ & & 0 & 0 & 0 & 0 & 1 & 0 & 1 & 0 & 0 & $\mathbf{0}$ & \\
\hline inal pain ... & 11 & 6 & 3 & 1 & 24 & 11 & 7 & 4 & 14 & 5 & $\begin{array}{r}10 \\
4\end{array}$ & 0 \\
\hline $\begin{array}{l}\text { Backache } \\
\text { Abdominal swe }\end{array}$ & 1 & $\begin{array}{l}1 \\
2\end{array}$ & 0 & $\begin{array}{l}4 \\
0\end{array}$ & $\begin{array}{r}11 \\
2\end{array}$ & $\begin{array}{l}3 \\
3\end{array}$ & $\begin{array}{l}4 \\
2\end{array}$ & 1 & $\begin{array}{l}0 \\
0\end{array}$ & $\frac{1}{2}$ & 11 & 0 \\
\hline $\begin{array}{l}\text { and discomfort } \\
\text { "Bearing-down", }\end{array}$ & 2 & 2 & 1 & 0 & 2 & 2 & 0 & 0 & 2 & 0 & 1 & 0 \\
\hline & 11 & 9 & 1 & 4 & 14 & 10 & 10 & 3 & 7 & & & \\
\hline Pruritus vulvae.. & 0 & 3 & 2 & 1 & 7 & 6 & 0 & 1 & 3 & 1 & 4 & 0 \\
\hline Vaginal discomfort & 7 & 0 & 0 & 1 & 6 & 2 & 5 & 3 & 1 & $\begin{array}{l}0 \\
0\end{array}$ & 11 & 0 \\
\hline $\begin{array}{l}\text { Frequency of mic- } \\
\text { turition }\end{array}$ & & 1 & 1 & $\mathbf{0}$ & & & 2 & & & & & \\
\hline & $\mathbf{0}$ & 1 & 0 & 0 & 2 & 2 & 1 & 1 & 4 & 2 & 2 & 0 \\
\hline Urinary incontinence & & 1 & $\mathbf{0}$ & 0 & 2 & 0 & 1 & $\mathbf{0}$ & 1 & 0 & 2 & \\
\hline
\end{tabular}

a history of family and personal proneness to psychosomatic disorders. As a group they showed less resistance to environmental and emotional stresses than the remaining $54 \%$. They were more disturbed by separation from their husbands, by housing difficulties, and by the general hardship of present-day conditions.

\section{Symptoms and Aetiology}

\section{Maladjustment}

Faulty Personal Relations.-Maladjustment to the husband was the commonest and most potent dynamic factor in the production of neurosis. (The relation with symptomatology is discussed below.) Inability on the wife's part to adapt herself to marriage was found to be associated with earlier faulty relations with one or both parents. Unconscious hostility to the husband and aversion to marriage often originated in an insecure childhood during which the patient's parents quarrelled or separated and the patient identified herself with her ill-used mother. Depreciation of the husband was sometimes the result of overevaluation of the father. Maladjustment between patients and their children appeared in all instances to be secondary to maladjustment to the husband or to the patient's own mother. Maladjustment to "in-laws" figured as a contributory stress factor in $16.3 \%$ of cases. In $2.4 \%$, where such maladjustment was the focus of the neuroses, there was evidence of psychosis in the husband's family, with abnormally hostile behaviour towards the patient.

Maladjustment to the Husband Related to Frigidity and Dyspareunia.- Of 56 patients maladjusted to their husbands, $53 \%$ did not experience orgasm and $26.8 \%$ complained of dyspareunia. In some cases fear of pregnancy contributed to the motivation of the symptoms, but in the majority the apparent frigidity and dyspareunia suggested the unconscious expression of resentment against the husband. Absence of orgasm appeared to represent their refusal to be reconciled - a physiological sulking-and dyspareunia, where severe enough to curtail coitus, served as a punishment for the husband and, at a deeper level, for the woman herself. 


\section{Sexual Frustration and Fear of Pregnancy}

Patients were considered to be sexually frustrated who, although their sexual impulses were within normal limits, rarely or never experienced orgasm. In seven of these cases the husband was wholly or partially impotent and in eight cases the husband's coital technique was faulty as a result of ignorance. Absence of orgasm appeared most frequently to be secondary to fear of pregnancy and to maladjustment to the husband.

Fear of pregnancy was observed in 71 cases, which included multiparae, recently married women wishing to postpone pregnancy on account of housing difficulties, and emotionally immature patients resistant to motherhood : $31 \%$ of these patients did not experience orgasm and $25 \%$ complained of dyspareunia. In none of these cases was a satisfactory contraceptive technique employed. Coitus interruptus was commonly practised. Some used pessaries in which they had little or no faith ; some made no attempt at contraception. In patients who practised coitus interruptus the habit was apparently a contributory mechanical factor to the absence of orgasm, but in all instances a psychological inhibition of orgasm was also demonstrable as an unconscious defence mechanism against pregnancy. Many patients expressed the belief that conception was possible only when orgasm occurred. Dyspareunia similarly represented an unconscious escape from risk of pregnancy

\section{Sexual Frustration and Abdominal Pain}

Abdominal pain of one kind or another was a common complaint among all these patients. In some cases it took the form of dysmenorrhoea of "spasmodic" or of "congestive " type ; in others it resembled and may in fact have been aggravated by "middle pain." In a few cases the duration of the pain and its relation to the period suggested endometriosis, especially when there were associated rectal symptoms and dyspareunia, but physical examination did not confirm the impression of endometriosis, and the symptoms later cleared up or changed in character. On several occasions the opportunity arose for direct examination of the pelvic organs by laparotomy, and it was possible to demonstrate the entire absence of the gross features of endometriosis and even to exclude it by histological examination.

The commonest type of abdominal pain encountered, however, was the so-called " pelvic pain," usually on the left side, dragging and aching in character, and occurring at all times in the menstrual cycle, though usually worse before or during the loss. In some of these cases there was tenderness on the left on vaginal examination but no evident gross pathology. Again, occasionally the opportunity has arisen to inspect the pelvic organs at laparotomy, and the absence of any gross organic cause for the symptoms has been demonstrated.

It may be that there is a physical mechanism for the production of pelvic pain in these people, especially where coitus interruptus is regularly practised without the relief of normal sex relations. The old theory of "pelvic congestion" may be invoked to explain the occurrence of pain, assuming that one ovary or tube becomes especially "congested" from repressed sex feeling. Low libido or distaste for sex relations was also a common finding in the same group, and it is not easy to correlate this with the presence of " ovarian congestion," unless one admits that a strong sex urge was present but was so deeply repressed that the woman was unable to recognize any feelings other than revulsion or lack of interest towards physical relations.

Abdominal pain appeared to be one of the most difficult symptoms to eradicate by anything less drastic than laparotomy. In some cases improvement was obtained by measures of reassurance alone, or by the help of physical measures, such as "D. and C." or cautery to a lacerated cervix, which were carried out as diagnostic points or in an attempt to relieve other symptoms but which in themselves could not have affected the pain. In several cases, however, one was compelled ultimately to resort to major surgery, with hysterectomy, in order to restore the woman to a condition in which she could tackle the burden of life in a reasonably fit state of mind and body. Hysterectomy of course solved other problems as well as pain, being especially applicable where there was a complaint of menorrhagia or a fear of pregnancy, and especially in women of 36 years or more who already had two or three children. Some women evidently have an unconscious desire for it. It has been suggested that the basic cause of many disturbances of genital function in which no organic cause can be found and with which is associated an anxiety state is a rejection of the implications of maturity - an unconscious desire for that phase of life when menstruation, sex function, and the possibility of pregnancy do not exist. Thus the patient with dysmenorrhoea is in revolt against maturity; the metrorrhagia and indefinite pelvic pain of the mature woman is a result of a subconscious need for the haven of the menopause. It does seem possible that in these women the uterus is a symbol of uncertainty and danger, and they will not be content or enjoy all life has to offer until that symbol of uncertainty has been removed.

\section{Other Factors}

Emotional Immaturity.-Patients were considered to be emotionally immature when their life histories showed that they had failed to emancipate themselves emotionally from their parents or from the precepts and prejudices of their childhood and adolescence. In 33 instances the degree of immaturity was such that the patients were incapable of adapting themselves to the realities of marriage and had developed neuroses as an escape from its implications. In 17 other patients problems arising from their immaturity contributed to their total anxiety load. The symptoms most commonly complained of by this group were : frigidity $40 \%$, dyspareunia $38 \%$, dysmenorrhoea $22 \%$, vaginal discharge $20 \%$, non-consummation $18 \%$, and infertility $18 \%$. The gynaecologist's physical findings in this group were analysed : $28 \%$ showed definite genital immaturity or " hypoplasia" and $20 \%$ vaginal discharge, $10 \%$ of which was infective. The incidence of other findings was insignificant.

Infertility.-This was a factor in the development of neuroses in 27 patients whose commonest complaints were absence of orgasm and dyspareunia. Patients in this group were often emotionally immature, and an unconscious resistance to motherhood was easily demonstrated in them.

Phobias.-Morbid fear of disease, chiefly venereal, tuberculous, or cancerous, figured as symptoms in the neuroses of 16 patients. In three patients the fear of venereal disease had its origin in emotional immaturity, and in three others in suspicion of the husband's infidelity. Patients with tuberculosis phobias were all strongly averse to further pregnancies. Their conviction that they were already infected, or would eventually develop the disease, served essentially as an excuse for the avoidance of pregnancy: usually the contraceptive method adopied was coitus interruptus. Five patients had cancerophobia; in each case it appeared to be secondary to sex frustration. In each of these five one could perceive a thinly veiled desire for removal of the pelvic organs; seemingly expressing the unconscious urge to escape the conflicts arising 
from their unsatisfied libido. A fear of cancer was possibly utilized at a higher level of consciousness as a means of rationalizing a repressed and unconscious dissatisfaction, and this substitution led in turn to various pelvic somatic symptoms, especially menorrhagia and pelvic pain.

\section{Social Problems}

Housing.-Unsatisfactory housing conditions were primarily responsible for the development of anxiety states in only two patients, who were constitutionally unstable, but in 57 patients the problem contributed to the total anxietyload and in many instances was related to symptomatology. The lack of privacy inevitable where a couple "lived-in with in-laws" was apt to lead not only to general friction, with possibly lasting maladjustment, but also to frigidity and dyspareunia. One often elicited the confession that the patient's aversion to coitus sprang from fear of being overheard. The same inhibition was observed, although less frequently, where parents and children were compelled to sleep in the same room. The wish to postpone pregnancy till a home was obtained was almost universal.

Separation from Husband.-The absence of husbands on national service rarely figured as a significant stress factor except in emotionally unstable patients and in those whose anxiety focused on their infertility. In pregnant women, on the other hand, separation from the husband was commonly the main dynamic component in the development of neurosis.

Inadequate Social Outlets.-Lack of adequate social and recreational activities was common. Many patients had not been out with their husbands since the birth of the first child. This has an obvious bearing on marital maladjustment.

Financial Stress.-The incidence was negligible.

\section{Psychiatric Treatment}

Psychotherapy was attempted in 84 cases in which there was reasonable expectation of response to short-term treatment. The average number of interviews per patient was seven over an average period of 15 weeks. In every instance of maladjustment between patient and husband the latter was invited to come for interview. This proved so welcome to the majority of couples concerned and was so effective in shortening treatment that it was decided to hold a monthly Sunday-morning clinic specially for husbands; where relations with other members of the family were faulty those concerned were invited to come for interview. This was particularly helpful in cases of overdependence on the mother.

Psychotherapy as such aimed at improved insight, better understanding of family relations, and the recognition by the patient of the influence of emotional conflict on physical symptoms. Treatment was mostly confined to explanation, re-education, and reassurance. At no time was special emphasis laid on the psychological nature of the treatment. In the majority of cases psychotherapy was given concurrently with physical treatment, and patients were encouraged to consider the psychiatric clinic as an integral part of the gynaecological department.

\section{Supplementary Measures}

Contraception.-All patients requiring contraceptive advice were referred during the first 12 months to the local Family Planning Association clinic. The prevalence of these cases and the desirability of all treatment being coordinated within the department led to the establishment of a weekly contraceptive clinic restricted to cases from the department.
Social Welfare Measures.-The services of the almoner are of course invaluable in this as in other branches of medicine. Each case in this series was considered in relation to social background, as much assistance as possible being given with problems such as housing, release of husbands from national service, change in husbands' working shifts, admission of children to day nurseries, and convalescent homes. Arrangements for a convalescent holiday, sometimes solely in order to remove a woman for a short time from an unsatisfactory environment, or for the care of children who are temporarily too much for the mother to handle, play a large part in making her better able to carry on with the stresses of life, and give her a chance to profit by psychiatric advice and to "see herself."

Minor Treatment such as that of a Trichomonas vaginalis infection, may remove a minor symptom around which a major complex has developed, but the complex is still there and needs further measures for its resolution. Investigation of infertility, and in appropriate cases recommendation of and assistance towards the adoption of a child, may be a keynote of success. In one of our cases the patient improved markedly when she was informed that her husband was infertile and that the responsibility for lack of a family could not be placed on her shoulders. In other cases investigation of the male, even though he proved apparently fertile, reassured the patient and gave one an opportunity for making the husband realize his position in the relationship between the basic worries and the actual symptoms produced thereby. In all cases, success with minor therapeutic measures was possible only so long as the major psychological complex was being examined and dealt with by reassurance and explanation.

Combined Therapy.--In a number of cases where it was apparent that the basic disturbance was a psychological one some improvement took place after a preliminary psychiatric investigation and some elementary treatment, but one or more residual symptoms remained. Sometimes one was satisfied that even these residual symptoms were psychogenic but resistant to psychotherapy, at least of a short-term nature ; in other cases it was possible that primary organic lesions were present, or that there had been a secondary development of physical changes in the pelvic organs which only radical treatment, usually surgery, would overcome. Other reasons for combined therapy included a number of dyspareunia cases where there had been long-standing difficulty, and where removal of the hymen, with perineotomy in many cases, was necessary in order that the still half-hearted efforts of the couple towards normal sex relations might encounter not even a minor physical barrier. Special comment is needed regarding one type of combined therapy-the case where successful psychotherapy must be allied with adequate contraception and where ordinary measures fail. Here surgical sterilization is justifiable and may be essential. The simplest procedure is tubal ligation, but in this type of case the unstable personality will persist and is quite likely to lead the patient at a later date into a further breakdown. It is therefore often desirable to proceed straight to subtotal hysterectomy instead of tubal ligation, as the former operation removes a potential source of further trouble with little extra risk.

\section{Discussions and Conclusions}

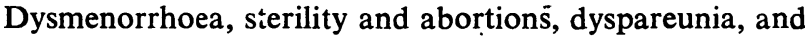
even uterine prolapse have been attributed, in whole or in part, to psychological causes (Rickman, 1926; Wittkower and Wilson, 1940 ; Wittkower, 1943 ; Kamman, 1946 ; Squier and Dunbar, 1946). Mayer (1937) has suggested that the gynaecologist is himself the ideal person to carry 
out the necessary psychological investigation and treatment, but he usually lacks the training required for such a task, and in any case the time element makes this impracticable in most hospital clinics. It therefore seems justifiable to include a psychiatrist and a psychiatric social worker in every gynaecological team. The psychiatric assessment and, so far as possible, the psychotherapy of a patient with well-defined gynaecological symptoms should take place within the framework of the clinic to which she has been referred, and it should not be necessary to divert her to another department, even in the same hospital. The importance of combined therapy has already been stressed, and this necessitates the closest co-operation between gynaecologist and psychiatrist.

Much neurosis with a genital background is attributable to ignorance and to faulty upbringing. In particular the incidence of frigidity and dyspareunia could be reduced by improved premarital education, including not only sex instruction but also general mental hygiene and the real value of family relations. Much unhappiness and even illness could be obviated by wider-and wiser-dissemination of proper contraceptive advice, with due regard to the temperament and character of the couple and to their religious beliefs. Midwives, health visitors, and even doctors often impress on patients the danger of further pregnancies without mentioning existing facilities for contraceptive instruction and without regard for the personal prejudices or ethical beliefs of the woman and her husband.

The prevalence of conditions of overcrowding, and the part played by ill-assorted family relations in producing many of these functional disorders, as outlined above, suggest that in some cases they might be regarded as equal with tuberculosis and other organic diseases in placing a couple high on the list of priorities for new houses.

Finally, in considering the relative importance of psychic and of somatic factors in the production of disease and disorder of the pelvic organs, and in reaching a decision on the method of treatment, a compromise must often be reached : as suggested by Deutsche (1947), the psychiatrist must always have the courage to give up, at the right moment, his own hopes of healing the patient psychically whenever the gynaecologist can eliminate an important defect more quickly ; and the gynaecologist must be prepared to withhold his knife and even his hormones when the psychiatrist advises that their use may have bad psychological results. He must also be prepared to operate, on some occasions, even in the absence of demonstrable organic disease, if his colleague can be reasonably sure that only removal of the uterus or repair of the pelvic floor will finally reassure the patient and abolish her anxiety state.

\section{REFERENCES}

Deutsche, H. (1947). " Psychiatric Component in Gynaecology," in Meigs and Sturgis's Progress in Gynaecology. U.S.A., William Heinemann, Ltd.

Kamman, G. R. (1946). J. Amer. med. Ass., 130, 1215

Mayer, M. D. (1937). Amer. J. Obstet. Gynec., 34, 47.

Rickman, J. (1926). Int. J. Psycho-Anal., 7, 363.

Squier, R., and Dunbar, F. (1946). Psychosom. Med., 8, 161.

Wittkower, E. (1943). Proc. R. Soc. Med., 36, 109. and Wilson, A. T. M. (1940). British Medical Journal, 2, 586.

According to a report which appeared in the Daily Telegraph of Aug. 17, the Airborne Forces Security Fund has financed a scheme for maintaining eight patients at a time in a special chalet attached to a sanatorium at Leysin, Switzerland. The scheme was devised for the assistance of 28 former paratroopers who are ill mainly as a result of prison camp conditions, and the arrangements at Leysin have been made because hospital accommodation was not available for many of these men in Britain.

\section{CENTRALIZED GONOCOCCUS CULTURE FOR DISPERSED CLINICS}

THE VALUE OF A NEW TRANSPORT MEDIUM FOR GONOCOCCI AND TRICHOMONAS

\author{
BY
}

MARY MOFFETT, M.B., D.P.H.

JEAN L. YOUNG, M.B., D.P.H.

AND

\section{R. D. STUART, M.D., D.Sc., D.P.H.}

(From the Public Health Venereal Disease Service and the Central Public Health Laboratory, Glasgow)

This paper considers the use of bacteriological cultural methods in the diagnosis and control of gonorrhoea when facilities for culture are not immediately available, and reports on the performance of a special method (Stuart, 1946) for maintaining the viability of the gonococcus in material which cannot be cultured for 12 to 24 hours after collection from the patient. The application of this method to the diagnosis of Trichomonas vaginalis infestations is also discussed.

When adequate bacterio'ogical facilities are available either within a venereal diseases clinic or immediately adjacent, gonococci can be cultivated from clinical material with comparative ease. The need for culture and the advantage of adding this procedure to stained smear examination have been stressed in many recent reports (Sewell, Salchow, and Nelson, 1943 ; Reymann, 1944 ; Eldering and Palser, 1946), but the administrative difficulties have too often proved insuperable. The bacteriological investigation of gonorrhoea requires a trained bacteriologist with specialized and expensive equipment, but the necessary dispersion of clinics in big cities renders this economically impracticable. The transport of unprotected swabs to a central laboratory is feasible, but this must be done very quicklywithin half an hour (Muir and Ritchie, 1937). Since work in clinics is often done in the evening and may last three or four hours, this would necessitate numerous journeys between the clinic and the laboratory and an enlarged laboratory staff-at increased cost. Other methods have been suggested, such as the transport of material in dry ice (Wortmann et al., 1941), in vacuum flasks (Christiansen and Becker, 1938), or surrounded by hot-water bottles (Malcolm and Dolman, 1939). Such methods are difficult to apply except under special circumstances, and most recent authors suggest the use of slopes of solid media or tubes of fluid media inoculated in the clinic and transported to the laboratory as soon as possible (Pitts, 1940 ; Carpenter, 1943 ; Peizer and Steffen, 1943). Reymann, however, points out that a major defect of these methods is the overgrowth of contaminating bacteria which frequently occurs. The inoculation of culture plates in the clinic and their primary incubation there. before transport to the laboratory is obviously equivalent to direct culture, but few clinicians have the time and experience to carry out efficiently the inoculation and incubation of culture media, and few of the simpler transport methods yield successful results if the swabs are delayed more than eight hours before culture (Carpenter, 1943 ; Morton and Lebermann, 1944).

In Glasgow we were faced with this problem of dispersed clinics in which a large amount of work was done in the evenings and from which material could rarely be brought to the central laboratory in less than 18 hours. The clinics were working under great pressure and the attending clinicians could not undertake any extra bacteriological work. Yet, particularly in the diagnosis and control of female 